\title{
BILATERAL MESIAL SUPERFICIAL "DEFICIENCY" OF THE SCLERA [SCLERAL PLAQUES]
}

BY

\section{BASIL Graves*}

Dr. Arthur M. Culler's article in the January issue of the Brit. Jl. Ophthal. (pp. 44-50) with its interesting clinical and pathological report on "Scleral Plaques," induces me to submit the following article bearing on this subject. I wrote this article nearly a year ago as the first part of one more than twice the length and, meaning to abbreviate it before submitting it for publication, I put it in a drawer where it has since lain. I now submit the first part for publication unaltered, save that I have inserted, in rectangular parentheses, some comments as the outcome of Dr. Culler's informative article. I have deleted the whole of the second portion as it is only very indirectly related to the subject under discussion, being concerned with the psychology of scientific observation and evidence.

In the Brit. Jl. Ophthal., October, 1937, pages 534 to 537, I wrote a short article [under the first of the two titles given above], describing some bilateral "defects" of the sclera. As the condition is bilateral and on the nasal side I had, without further consideration, and through habits indelibly ingrained in medical-student days, jumped to the conclusion that it was a developmental defect and it will be noted (p. 537) that when a patient (incidentally a very intelligent person) had told me that this condition had been observed in her eyes by herself and her friends only in the preceding six months I had, with a sweeping professional assurance that turned a deaf ear upon her evidence, and that found no difficulty in supporting dogmatism with suitable "explanations," replied that it must have been present in her since birth. $\dagger$ A week or two after the publication of this article I met Miss Ida Mann and she asked me whether I had considered that the condition, one affecting seemingly elderly people, could be due to a hyaline degeneration of the sclera without any structural thinning such as I had suggested might be present. [It will be noted that the idea of hyaline degeneration occurred to

\footnotetext{
* Received January 9, 1939.
}

† Compare the answer, in the case of Jane Throgmorton's convulsive fits (1589), given by Dr. Barrow, a celebrated physician of Cambridge, who, " perceiving the Child's Body to be in good Temper, which appeared for anything he saw to the contrary, asked if there was no Sorcery or Witchcraft suspected in the Child, to which they answered, No. Upon which he declared it was impossible it should be occasioned by any natural Cause, without any Signs appearing in the Urine: Nevertheless he desired they would send to any other skilful Man in the Town for their Satisfaction ": vide the accounts of the accusation, trial and execution for Witchcraft of the Samwell family of Warboys, Huntingdonshire, in Thomas Wright's " Narratives of Sorcery and Magic" (1851) and Boulton's "Compleat History of Magick, Sorcery, and Witchcraft" (1715). 
Dr. Culler.] This possibility had not occurred to me. Should this prove to be the case, and if further reports should confirm that the condition is confined to the nasal side of the sclera, it would be a significant matter for interesting conjecture as to whether the predisposition to such hyaline change in later life is potentially present from the embryonic period; I add this only as an afterthought and not with any intention of defending my probably erroneous suggestion that the condition is " congenital " in toto.

After I had written the article in the Brit. Jl. Ophthal. for October, 1937, I came upon a record of another case, the existence of which I had forgotten. It is reproduced in Fig. 1. (The measurements recorded are $A$ to $B$ and $F$ to $G$, each $35 \mathrm{~mm}$.;
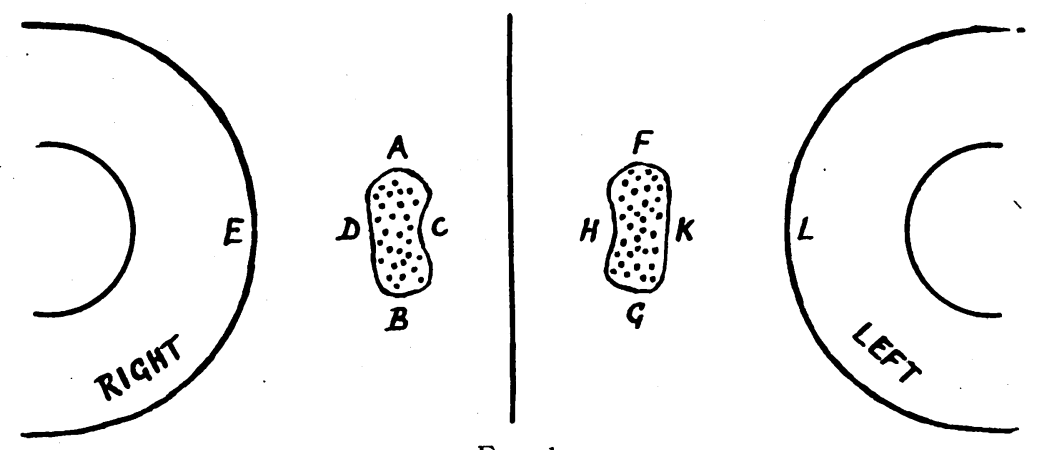

FIG. 1.

Symmetrical mesial scleral deficiencies [plaques].

$\mathrm{C}$ to $\mathrm{D}$, i.e., width at the narrowest part, $1.4 \mathrm{~mm}$. $\mathrm{H}$ to $\mathrm{K}, 1.6$ $\mathrm{mm}$.; D to $\mathrm{E}$ (limbus) and $\mathrm{K}$ to $\mathrm{L}$ (limbus), each $3.0 \mathrm{~mm}$. The age of the patient was unfortunately not recorded but she was suffering from a recent attack of paresis of the third nerve, which 1 recorded as due to " ? cerebral vascular change," so she was probably elderly.) The bilateral symmetry in this case is rather striking.

In the opening words of my previous article I referred to a case which I had briefly indicated in "The Eye and its Diseases," edited by Dr. Conrad Berens, at Fig. 184, H, page 467. In a footnote on page 468 of this book I had implied that in this particular case the condition was not bilateral. In all the other cases which I had seen the condition was bilateral. Shortly after the occasion of Miss Mann's comment, this particular patient, whom I had not seen for some time, came back to me, and I looked at his sclerae and discovered that in this case, too, the condition is bilateral. Fig. 2 shows this, and differs from the figure reproduced on page 467 of Dr. Berens' book in having the two defects $\mathrm{M}$ and $\mathrm{P}$ added in the right eye. Whether the 
defects $\mathrm{M}$ and $\mathrm{P}$ were present but overlooked when I first recorded this case (some years ago), or whether they have developed since, I cannot say, but reference to the figure in Dr. Berens' book will show that certain changes in the periphery of each cornea were present at the time the original records were made. It will now be seen that the corneal changes are radially opposite the areas of scleral defect and had I originally noticed that the scleral defects were bilateral I think it possible that I might, from their correlation with the corneal changes, have drawn the conclusions I am now going to suggest. The following details (except the scleral defects $M$ and $P$ ) were recorded in my original notes of this case and when I saw the patient again after I had published my short article in the Brit. Jl. Ophthal. for October, 1937, I did no more than take a brief glance in which I detected the presence of $M$ and $\mathrm{P}$ and confirmed that the corneal condition was substantially the same as when previously recorded.

The patient bears the name, and is the nephew, of one of the best known British ophthalmologists of the early nineteenth century. He is now 94 and is in clear possession of his mental faculties and gives many interesting reminiscences of the middle of the last century among which he recalls that a great friend of his father's stayed at their home before leaving for the Crimea, and that not long afterwards a telegram arrived announcing that this friend had been killed while second-in-command at the Charge of the Light Brigade.

The measurements of the defects (Fig. 2) and of their distance from the limbus is as follows : $M$ (vertically), $0.9 \mathrm{~mm}$; $\mathrm{N}$ (space between $M$ and $P$ ), $1.2 \mathrm{~mm}$.; $P$ (vertically), $1.8 \mathrm{~mm}$.; $R$ (distance from limbus), $3.5 \mathrm{~mm}$.; $\mathrm{T}$ (vertically), 1.75 mm.; W (vertically), $2.5 \mathrm{~mm}$.; $\mathrm{T}$ and $\mathrm{W}$ (horizontally), each $1.4 \mathrm{~mm}$.; $\mathrm{X}$ (distance from limbus), $2.5 \mathrm{~mm}$.

It would unduly prolong this article to give a full account of the corneal features and I will describe them only in so far as they seem to throw light on the scleral condition. 
(An adequate account of the corneal changes would call for a separate article on " senile grooving" of the cornea which at one time interested me as affording the basis of many speculations on the significance of the almost perfectly circular and abrupt limitation of Bowman's membrane, a structure of interest because clinical evidence reveals that when considered from certain points of view it behaves clinically as might be expected from the histological entity it is known to be, but from other points of view it seems to react to influences in a manner no different from that of the stroma immediately deep to it.)

The lines drawn in the cornea at $S$ and $Z$ (Fig. 2) represent the limits of a type of change represented in the optical section, Fig. 3, which depicts this limitation as a line $\mathrm{YZ}$ (extrasectional) cutting the optical section at $\mathrm{D}$, i.e., about the level of Bowman's membrane. Though this particular change, casually inspected, is sometimes regarded as deep " grooving" of the corneal periphery, because of the " eroding " of the stroma to the level of the dotted line $\mathrm{K}$, it is entitled to be called "grooving" only in so far as the epithelium, F, fails to rebuild the corneal surface to its normal contour-level. In this case (left eye) the optical section shows a slight surface flattening of this nature between $\mathrm{D}$ and $\mathrm{E}$, and a similar condition is seen in an optical section of the peripheral region (F, Fig. 2) of the right eye. But in the case of the two additiona! small oval areas (near the letter S, Fig. 2) the eroded stroma is adequately replaced by epithelial proliferation so that, at any rate over these, the normal corneal contour is maintained. This capacity of the corneal epithelium to reproduce the normal surface contour over underlying "erosion" or atrophy of the stroma is well known, but what happens at the junction of the stroma and the basal epithelial layer to account for the fact that the epithelial replacement is full in some regions and inadequate in others is, I presume, not known. Another feature will be noticed in the optical section, Fig. 3 : the normal epithelial thickness, depicted between the surface line A and Bowman's membrane $\mathrm{B}$; becomes reduced (C) in the region approaching the area of main pathological change and this is obviously of interest as suggesting whether initially this whole pathological change might be one occurring in the basal epithelial cells or whether it is primarily in the superficial stroma though as yet producing no visible change in the stroma at $C$. If, as I shall suggest, the scleral defects are to be correlated with this "eroding "stromal change of the cornea the primary change is inferentially a stromal one since there is no basal epithelium in immediate contact with the surface of the sclera. [It is interesting to note that Dr. Culler found, in his histological sections through a scleral plaque, that " the conjunctiva and episclera were atrophic. A few globules filled with granular debris were seen lying immediately under the epithelium." (Brit. Jl. Ophthal., January, 1939, p. 45.)] In Fig. 3 (which I have drawn only roughly, when without proper 


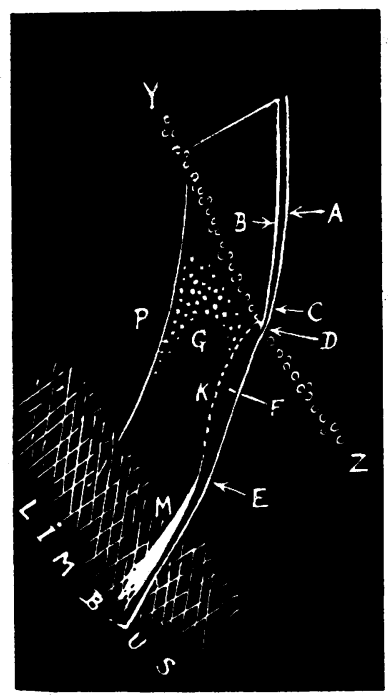

FIG. 3.

Optical section through the region $\mathrm{z} x$ of Fig. 2.

drawing instruments) the coarse dots above the letter $G$ represent the arcus senilis in optical section.

The most significant feature of this case is to be found in the demarcating line $\mathrm{YZ}$ (Fig. 3) corresponding to the line $\mathrm{Z}$ in Fig. 2 . It cuts the optical section about the level of the eroded edge of Bowman's membrane and by retro-illumination it consists of numerous highly refractile droplets suggestive, in their brightness, of "oily" droplets; and, unlike the slightly refractile vacuoles commonly seen in the epithelium of the cornea (which by retro-illumination show " unreversed" illumination) these droplets show " reversed" illumination.

These terms " unreversed " and " reversed " may here be explained more fully than was possible in the space available in Dr. Berens' book. I first used them in print on page 512 of the Brit. Jl. Ophthal. for November, 1924. The article had to be produced at short notice in compliance with the terms of a research scholarship which had terminated and my difficulty and slight delay in rendering the report lay, not in any lack of information but in selecting what to report out of a profusion of accumulated records. I therefore chose, at random, to report the interesting subject of what has since been named "cornea guttata." I had first noticed a very coarse and advanced case of this condition (Fig. 4) about 1921 or 1922 and I eventually found other but much finer examples-in which the changes at the back face of the cornea are fine isolated punctate ones (Fig. 9)-by examining the elderly inmates of an infirmary. It sounds a simple question now-as all observations are after they are confirmed-but for some time after first seeing this condition of cornea guttata I found it difficult to decide whether they were pits in, or prominences of, the back face of the cornea. At that time I had no further access to proper clinical work or I should have examined all available cases of enucleation-which in an eye hospital can doubtless amount to over 100 a 


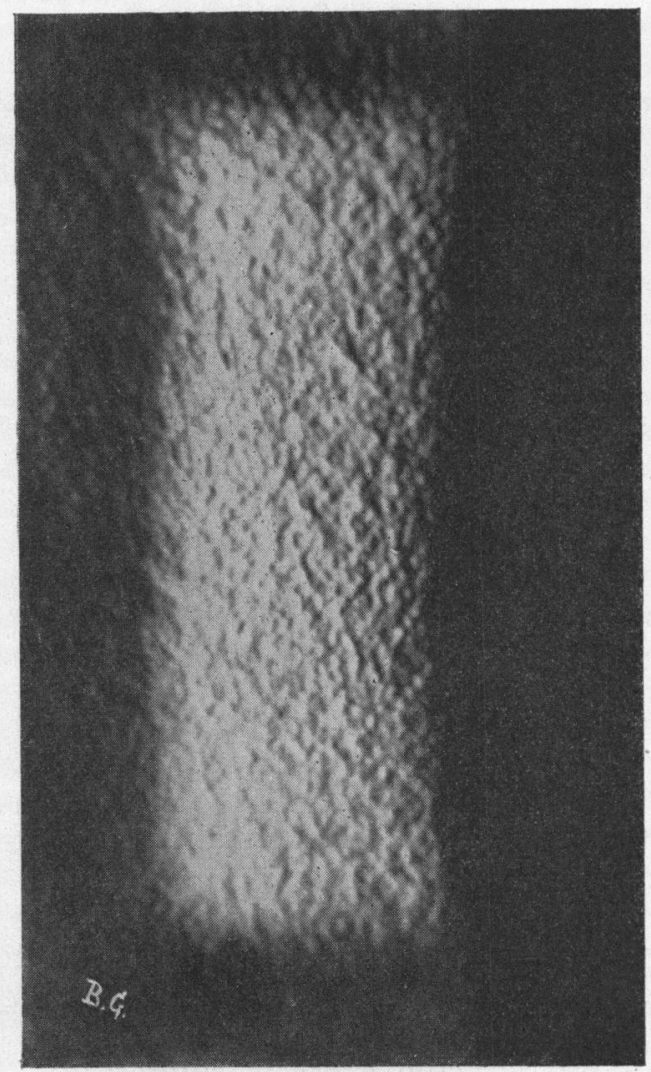

Fig. 4.

Diagrammatic representation of a very coarse and advanced case of cornea guttata by retro-illumination. Technically, this diagram is inaccurate; the individual refractile irregularities (nodules) on the east side are incorrectly por trayed as having " unreversed " instead of "reversed " illumination ; and this pathological lesion should be portrayed in greater evidence in the region immediately ad joining the retro-illuminated area (indirect retro-illumination: compare the balls of K.P. indicated by $P$, Fig. 8) instead of, as here depicted, in the region of direct retro-illumination in front of the lightpatch (compare S, Fig. 8).

year-and with probable success, since, in 1934 Dr. Everett L. Goar stated (in the Amer. Jl. of Ophthal., vol. 27, p. 215) that in 800 patients above the age of twenty he had found cornea guttata in about $6 \%$. The histopathology of the condition was eventually described. Failing the possibility of getting information through histological means I had sought to interpret the optical appearances by retro-illumination of the little punctate features in cornea guttata as follows:

If ordinary vacuoles in the corneal epithelium or the lens cortex are examined by retro-illumination, it will be found that they show " unreversed " illumination, e.g., Fig. 5, which shows vacuoles in the anterior lens cortex seen against a small cylindrical beam of light traversing the lens-substance behind them: their light side is over against the light-beam. The same optical property of 
" unreversed " illumination is revealed, faintly, in the specific condition which I have tentatively suggested should be called " superficial reticular "vacuolation " " (Fig. 6), and in the very fine elements of "cornea farinata " (Fig. 7) which are just within the resolvable limits at which this question can be decided. Now balls of precipitates on the back of the cornea show " reversed " illumination (Fig. 8), as do the punctate features of "cornea guttata," as indicated in the diagram, Fig. 9. A detached sphere of soft lens-matter suspended in a hernia of the vitreous in the anterior chamber after needling similarly shows "reversed" illumination. With this information collected, I attempted, in that early period, to get help to interpret these appearances of retro-illumination. Not long before that, and before I knew of the existence of the slit-lamp, I had been empirically seeking after some means of a restricted or punctate illumination of the eye ( $\mathrm{I}$ had got assistance from various sources outside the medico-surgical profession, one in particulat being a firm which then was concerned with the illumination of London theatre stages). In this, as also a little later in attempting to interpret the appearances of retroillumination, I derived no help whatever from the orthodox text-book treatment of optics or from any medical authority who adhered to this conventional

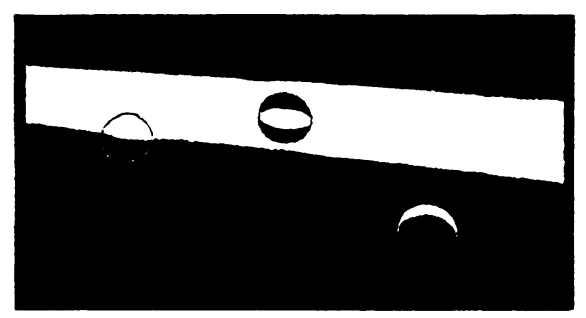

Fic. 5.

presentation of the subject. I had taken up ophthalmology as the result of being an undergraduate student at the hospital to which Mr. Treacher Collins was ophthalmic surgeon. He retired from his hospital appointments just at the time that I eventually began to aspire to the clinical research of the type I am describing. He was essentially a man of independent thought, in no sense an imitator and above all a "craftsman" who would amuse himself making his own inductive observations and doing his own drawings of pathological conditions. He was the antithesis of the type of mind that elects to ponder on the work of other people and destructively to criticise from a theoretical elevation the work of the " practical" innovator. Most students who worked with Mr. Treacher Collins before he retired from hospital work in 1922 will probably recall the encouraging enthusiasm with which he received any new clinical suggestions or ideas, and his generous treatment of all those who made them. His mind was not closed by dogmatic systems and I think it probably not incorrect to say that he was not a great reader of the work of other people : he knew little of any foreign language. It would be interesting if anyone historically minded reviewed all Mr. Treacher Collins' published work to see how far it may bear out these personal characteristics, due allowance being made for the fact that it is impossible to gauge with historical accuracy the cross-currents of intermental thought of society meetings from the official published records in which, consciously or unconsciously, modifications and proof corrections of the papers and of the discussions can have drawn a red-herring across the trail of the significant events. It was in this spirit of inductive approach that Mr. Collins bought a slit-lamp after he nad retired from hospital and would come down to learn its use of an evening at the Royal Westminster Ophthalmic Hospital where I was working for a short time. I discussed these questions of retro-illumination with him (I had already approached microscopists without any success) and I remember always his interest in the following empirical way of elucidating them which any reader may repeat for himself. 
Basil Graves

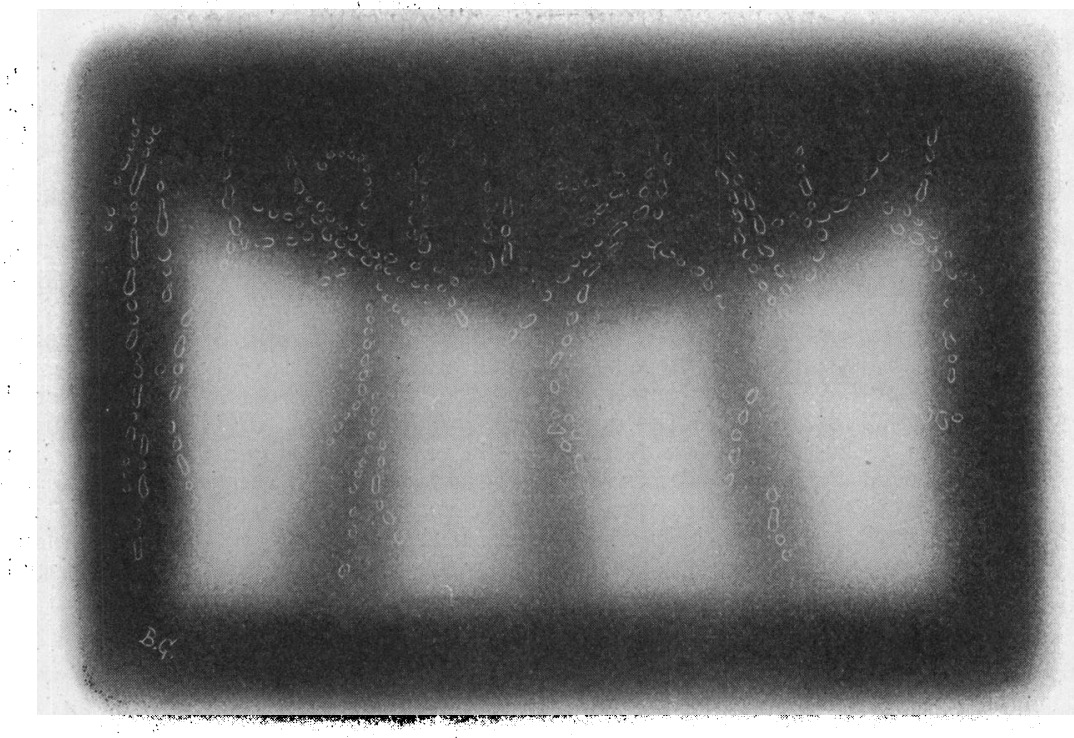

Fig. 6.

Reticular superficial "vacuolation" of the cornea.

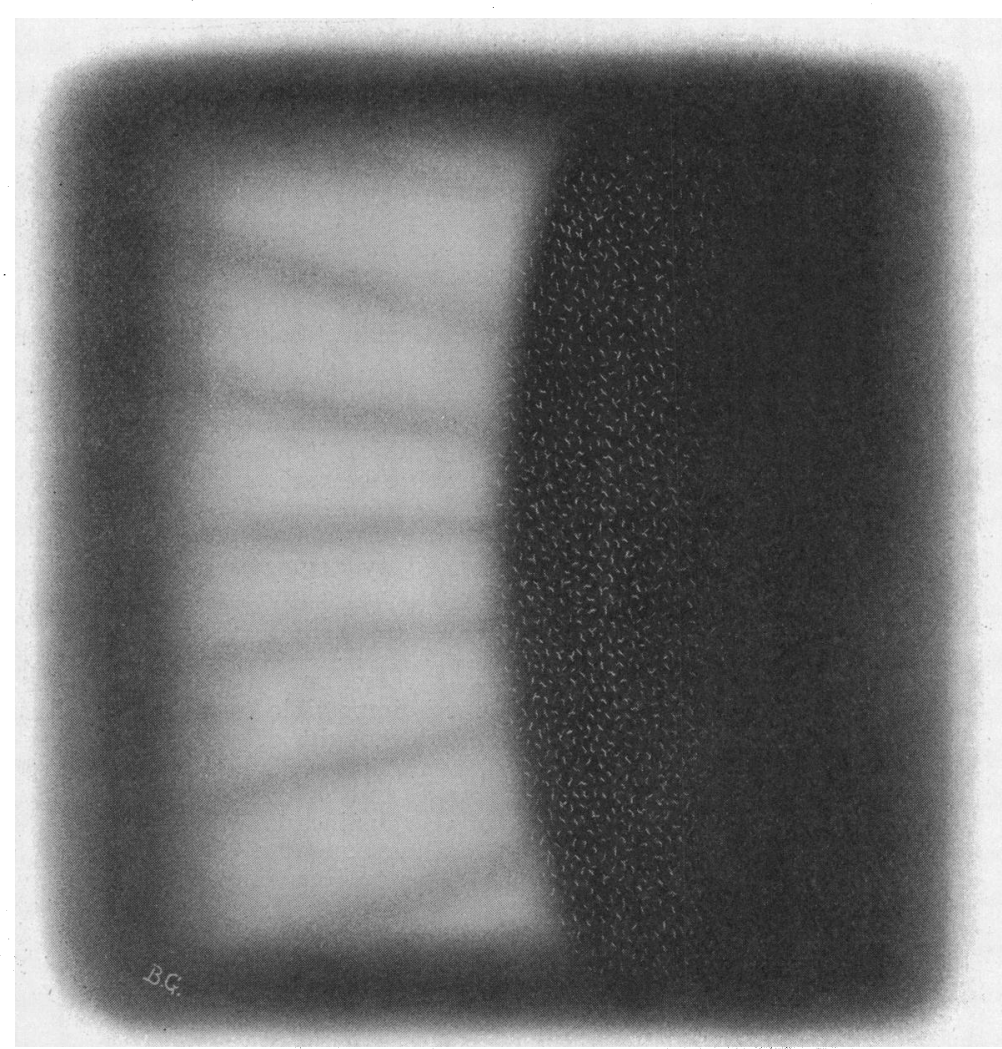

FIG. 7.

Cornea farinata.

(1) 
Superficial "Deficiency" of the Sclera

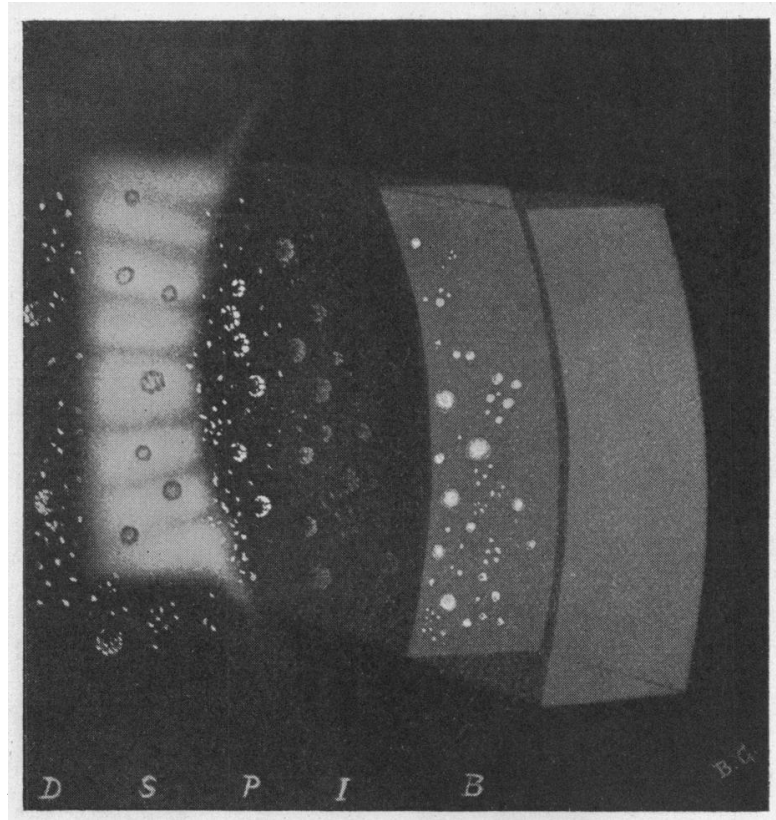

FIG. 8 .

K.P. by retro-illumination and by direct illumination (and visible " flare" in the aqueous fluid).

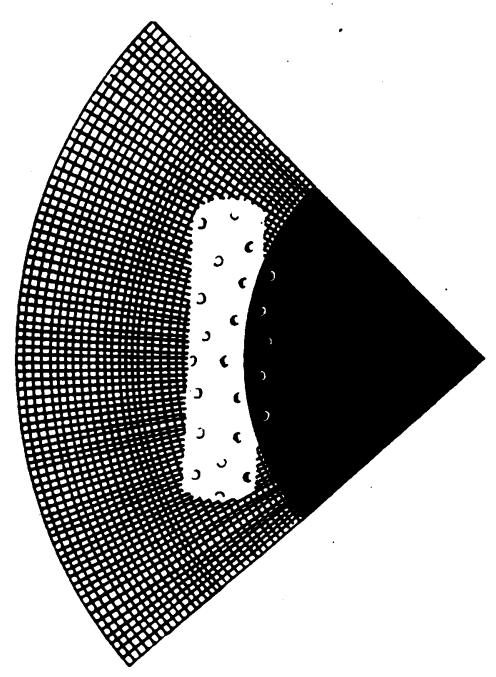

FIG. 9.

Mild Cornea Guttata (diagrammatic). 
Numbers 1 to 12 used in the ensuing remarks refer to Fig. 10. Place a white sheet on a black ground, as depicted in each of the small drawings of Fig. 10. Hold, say, a $3.0 \mathrm{D}$. convex lens at some little distance in front of the boundary between black and white (1); move the lens a little eastward: the boundary moves a little westward (2). Move the $3.0 \mathrm{D}$. lens more eastward and the
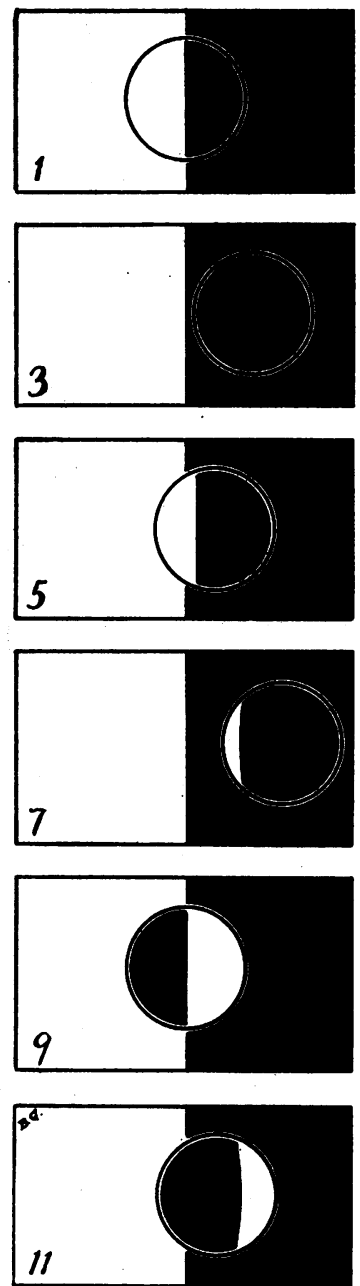
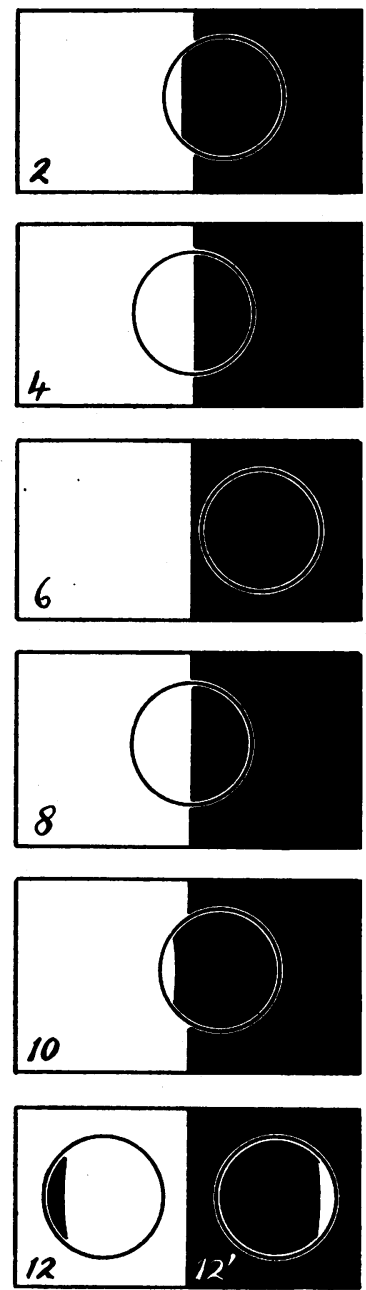

FIG. 10 .

boundary is no longer seen in the lens (3). Repeat this with, say, a 3.0 D. concave lens $(4,5$ and 6$)$. Repeat 4,5 and 6 with, say, a 16.0 D. concave lens, when the boundary is still seen in the lens (7) even though the lens is displaced considerably eastward. Now compare the diagram 7, with the picture of " unreversed illumination" of lens-vacuoles (Fig. 5, page 197). Now take a strong convex lens, say $16.0 \mathrm{D}$., hold it first quite close to, but not touching, the background as in $\mathbf{8}$, and then, keeping it opposite the boundary-line draw it further away from the background (9) and note that suddenly, at and beyond a certain distance the light and dark background as 


\section{Superficial "Deficiency" OF THE Scleka}

seen in the lens become reversed. Note that if this is done with a strong concave lens no such reversal occurs, no matter what distance the lens is from the background. Now move the 16.0 D. convex lens eastward while still holding it close to the background: there is no reversal (10). Next bring it further away from the background before moving it eastward and note the "reversed" illumination (11 and 12 ') and compare this with the precipitates and cornea guttata in Figs. 8 and 9, page 199.

Returning for a moment to Fig. 10, it is seen that 7 (concave lens) represents " unreversed " illumination and 12 and 12' (convex lens held sufficiently far off) represent " reversed" illumination. But two difficulties stood in the way of inferring from this the nature of corneal and other conditions by retroillumination. First, it was not likely that vacuoles in the corneal epithelium and the lens cortex would be biconcave; and, at any rate, in the case of the cortical lens-vacuoles, some are not infrequently big enough to disclose their convex shape in optical section, as in A, B, Fig. 11; also, histology had for years already afforded evidence of their spherical nature. Consideration of
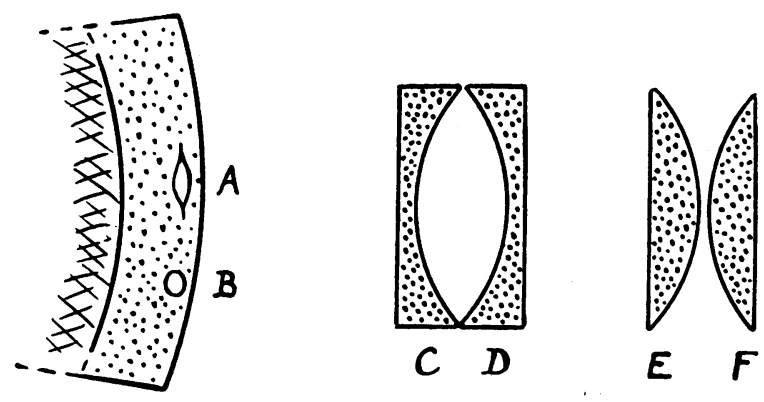

FIG. 11 .

this at once suggested that their " unreversed" illumination might be explained by assuming that their refractive index, instead of being greater than that of their surrounding medium, might be less. On placing two planoconcave lenses together as one C, D (Fig. 11) so as to make a "lens" of air within glass, it was at once obvious that such a combination showed unreversed illumination as did the biconcave lens in diagram 7 of Fig. 10. But, secondly, there still remained the difficulty-as regards deciding whetler the punctate features of cornea guttata, which always show reversed illumination, were depressions or elevations-that a convex glass lens shows either unreversed (diagram 10) or reversed (diagram 12') retro-illumination according to the distance by which it is separated from the illuminated background.

Whilst still in doubt, and when not hopeful of being able to get facilities for histological evidence, an idea occurred to me one evening when I was not particularly contemplating the subject: I have referred to it on pages 527,528 of the Brit. Jl. Ophthal. for November, 1924, and briefly, on pages 456 and 472 of Dr. Berens' book, "The Eye and its Diseases." It was that the difference in the axes of the Czapski microscope, owing to the convergence of its right and left halves, could be used to determine as to which way the reflecting rim of these little corneal changes was inclined and from this it could readily be decided if they were convexities or concavities. That same evening I examined a friend who, I knew, had cornea guttata, definitely ascertained for the first time that they were convexities and thereby also secured a key to settling the various difficulties in the way of understanding the question of " reversed " and " unreversed " retro-illumination in different clinical conditions and also a means of correlating these appearances with those of Fig. 10. I rang up Mr. Treacher Collins and he told me to come to his house then and explain the details to him. They are a matter of little import now, but I shall always remember the interest with which he received the information. (A story, doubtless aprocryphal, used to be current that the 
late Basil Lang, when House Surgeon to the late Mr. Holmes Spicer, rang him up at 4.0 a.m. to say that a retinal detachment had gone back into place; it was not recorded how the information was received.)

It was now clear that various spheroidal or biconvex or plano-convex changes occur in or on the cornea and the lens-cortex showing " unreversed " retroillumination when their refractive index is lower, and "reversed " illumination when their refractive index is higher, than that of the medium with which they are in contact.

The line $\mathrm{Z}$, of Fig. 2 ( $\mathrm{YZ}$ of Fig. 3) which demarcates the edge of the stromal "erosion" F (Fig. 3), and the corresponding lines shown at $\mathrm{S}$, Fig. 2, reveal, as I have said above, numerous highly refractile droplets, about the level of the eroding edge of Bowman's membrane. These droplets show reversed retro-illumination, i.e., they are of a material (? hyaline or fatty) which, unlike that of ordinary vacuoles in the corneal epithelium, is of a higher refractive index than the tissue in which they are imbedded. That they are highly refractile is indicated by the fact that the reversed illumination shines in them when the retroillumination is far removed from them in a lateral direction (compare Fig. $10\left(12^{\prime}\right)$ in which a strong $(+16)$ lens is used). The details of this case now suggest the correctness of the proposal [of Miss Mann and Dr. Culler] that the scleral defects may represent a hyaline change. Even so, it is feasible that the scleral defect involves an actual thinning since there is no epithelium in close contact with the sclera to make up the thickness as it does in the cornea (F, Fig. 3). The highly visible edge of these scleral defects by proximal illumination could readily be accounted for on the ground that they may be areas of active dissolution of the fibrous tissue into a refractile material like that of the corneal droplets ; furthermore, the salients shown at C, Fig. 2, p. 535, of the Brit. Jl. Ophthal. of October, 1937, and at T in Fig. 2 in this present article, are in keeping with a possible solvent erosion by lateral spread. This Fig. 2 is also suggestive of the possibility that separate foci of the condition might spread and unite. [It will be noted that the scleral plaque in one of Dr. Culler's cases appeared two-lobed.] This condition does not seem to spread to the deep layers of the sclera but is apparently confined to the superficial part as in the cornea. [Dr. Culler's histological report indicates that the condition can involve the sclera to a considerable depth, see Fig. 3, in his article facing p. 47, Brit. Jl. Ophthal., January, 1939.]

Some years ago this patient had, in the left cornea, a little down and in from the centre, a condition which I have not seen previously. A small elevation protruded, like a raspberry; about $2 / 3$ rds of a millimetre in diameter from the surface (Fig. 12). Around its site were a number of grotesquely shaped little white plaques at the level of Bowman's membrane. He complained of irritability and I asked him to return next day when I intended 
to carbolise the small proturberance. When he came back next day it had gone and the epithelium at the site revealed a little defect of the surface suggesting that a sessile stump by which this proturberance might have been attached had broken off. The white plaques, unchanged, have been present ever since. [The term " plaques " as used here should not be taken to imply that the features of Fig. 12 had any refractile properties resembling the changes described under Figs. 1, 2 and 3 in this article which, optically, are very different.]

[Dr. Culler's article in the Brit. Jl. Ophthal. for January, 1939, affords conclusive and interesting evidence on the histo-pathology of this lesion of the sclera.] The case which I have just described, revealing related corneal changes, affords evidence which could be used as the jumping off point of various conjectures. In no science can we initially know what is important and what is unimportant. Imagine, hypothetically, the exaggerated supposition that an authority on histopathology should insist that the only avenue along which sound advance can take place in ophthalmology is through the channels of the laboratory examination of dead eyes. The mesial scleral lesion here referred to would then

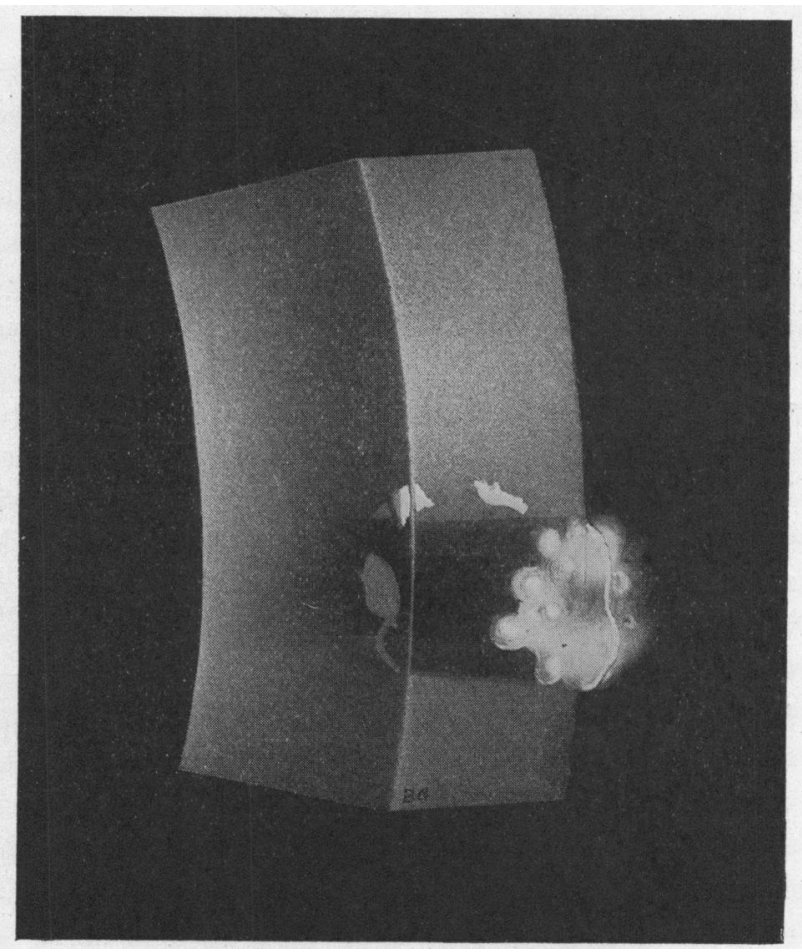

FIG. 12 . 
not have been recorded owing to the mere accident that it is customary to bisect dead eyes vertically and not horizontally. Correspondingly, clinical evidence alone could not suffice to clarify this condition. The whole history of medicine and surgery reveals the desirability of permitting various observational and inferential avenues of approach to its never-ceasing potential problems.

[Two or three weeks ago (January, 1939), and shortly after submitting this article for publication, I have come upon another case in a man aged 66 years. The mesial plaques are very noticeable (being extra dark) in ordinary daylight, but they are not very evident when a small beam of light is focussed on to them; and their edges do not then show up sharply in the manner described in my article for October, 1937. The left plaque (Fig. 13) measures $4.7 \mathrm{~mm}$. vertically by $2.5 \mathrm{~mm}$. horizontally and is $2 \cdot 2 \mathrm{~mm}$. from the limbus. A vessel
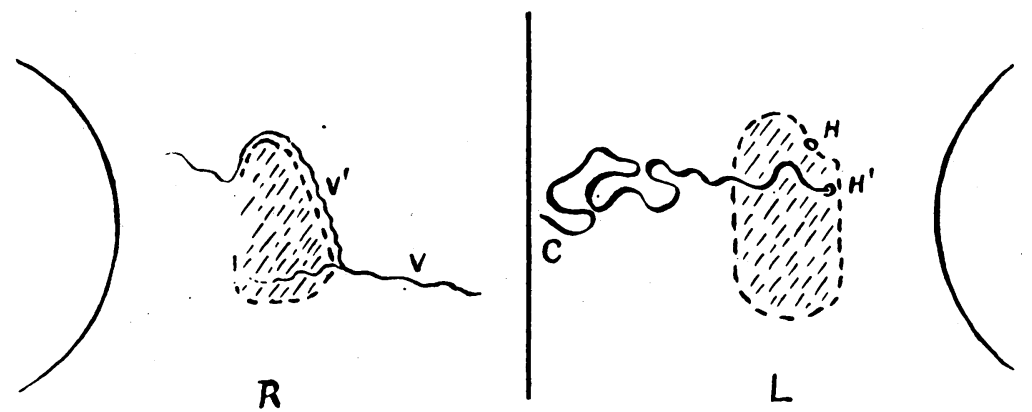

FIG. 13.

Mesial Plaques.-In this figure the diameter of the limbus has been drawn incorrectly, rather too small in proportion to the size of the plaques.

runs in the overlying conjuctival tissue from the region of the inner canthus $\mathrm{C}$ and enters a perforating hole, $\mathrm{H}^{1}$, at the edge of the plaque. Above this, at the edge of the plaque, there appears to be another perforating hole, $\mathrm{H}$, containing no vessel. The right plaque is triangular, though its demarcation towards the corneal side is ill-defined. It measures vertically $3 . \tau \mathrm{mm}$. by $2.5 \mathrm{~mm}$. at its broad base, and is $2.6 \mathrm{~mm}$. from the limbus. A conjunctival vessel $\mathrm{V}$, after sending off a small branch which crosses the lower part of the plaque, continues on a course $\left(\mathrm{V}^{1}\right)$ which follows the contour of the plaque for some distance. There is a strong suspicion (I cannot be certain owing to the relative faintness and to the presence of pingueculae) of a smaller dark area in each eye on the temporal side, slightly below the mid-horizontal level. In each case the distance separating these possible lateral plaques from the limbus is greater than is the case with the mesial plaques. In the left eye the distance is $4.7 \mathrm{~mm}$. and in the right eye $4.3 \mathrm{~mm}$. There are no such signs in relation to the superior and inferior rectus insertions. This is the only instance in which I have seen lateral plaques.] 